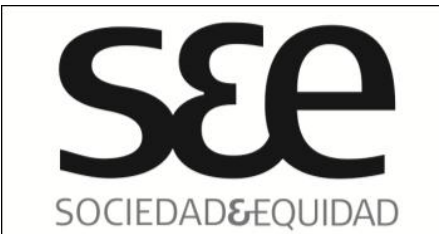

SOCIEDADEEQUIDAD

\title{
Por una política sexual de las diferencias
}

\author{
Towards a Sexual Politic of Differences
}

\begin{tabular}{ll}
\hline Nombre: & Manuel Durán Sandoval ( ${ }^{1}$ ) \\
Filiación: & Becario CONICYT \\
País: & Chile \\
Correo: & manadura@gmail.com
\end{tabular}

\section{RESUMEN}

El presente ensayo nace de la discusión sobre "políticas de la igualdad", en el marco de los movimientos ciudadanos en Chile. $\mathrm{Y}$ apunta a evidenciar los mecanismos de reconocimiento que los movimientos gays y las políticas asimilacionistas han adoptado, en su negociación con el sistema Patriarcal, heterosexista y Liberal.Dichas negociaciones dejan fuera de rango muchas prácticas e identidades sexuales divergentes, generadas fuera de las relaciones formales de la afectividad. Por lo que debemos preguntarnos si ¿Estamos dispuestos a asumir los mismos programas de normalización sexual y afectiva de la hetero-normatividad a riesgo de generar nuevas exclusiones? En este contexto las políticas queer podrían significar una propuesta de alternativa, ante las políticas asimilacionistas y matrimoniales de los movimientos gay, estableciendo una "nueva Ética de las Afectividades".

\section{ABSTRACT}

This essay rises from the discussion on "Policies of equality", regarding citizen movements in Chile. It seeks to visualize the mechanisms of recognition of the gay movements and the assimilation policies they have adopted, in their negotiation with the liberal, patriarchal and heterosexist system. Such negotiations exclude many diverging sexual practices and identities that take place outside of formal emotional relations. We have to ask ourselves if we are willing to assume the same programs of sexual and affective normalization of hetero-normativity, and risk generating new exclusions? In this context, queer politics might mean an alternative proposal, considering the assimilation and marriage policies of the gay movements, establishing a "new Ethic of Affectivities".

PALABRAS CLAVES: Masculinidad, políticas queer, género, estudios gay

KEYWORDS: Masculinity, queer politics, gender, gay studies

\footnotetext{
${ }^{1}$ El autor es candidato a Doctor en Estudios Americanos mención Historia de la Universidad de Santiago de Chile. Becario CONICYT.
} 


\section{S\&e \\ SOCIEDADEEQUIDAD}

\section{Introducción}

Al principio de la evolución social los individuos semejantes se reunieron en un grupo, y los desemejantes se separaron, bajo la acción de las fuerzas incidentes, de un modo análogo a como hemos visto se agrupan y separan los seres inferiores.

Spencer. Primeros Principios.

Asistimos a un momento de transformaciones culturales trascendentales en la historia de la humanidad, caracterizado por el surgimiento de movimientos sociales globalizados, donde cada llamado a movilización recorre miles de kilómetros traspasando fronteras, etnias, culturas, género y muchas trabas que en los tiempos de antaño parecían infranqueables. Internet nos ha unido en una red de conexiones llamada el espacio virtual y desde estos márgenes armamos nuevas sociabilidades. Esperamos atentos el desenlace de estos movimientos que han llegado a este lado del hemisferio como viento y remolino haciendo girar todo.

En nuestro país se han suscitado acontecimientos similares y en esta vorágine hemos quedado un tanto desorientados; la sorpresa y, al mismo tiempo, la alegría, nos han bloqueado a muchos. Hemos dejado atrás la era de los Supra Estados e incluso la autoridad del mercado ha quedado cuestionada por este nuevo actor encarnado en la sociedad civil. Desde esta orilla se están fraguando nuevas inquietudes, nuevas formas de hacer política que exigen un pronto reconocimiento. Pero el peligro es que no podamos asir con fuerza nuestras posturas traicionando el espíritu de esta movilización; y le llamo movilización en singular, pues creo que todas las demandas que se han planteado a lo largo de los últimos meses de este año 2011 en Chile, y que yacían latentes por generaciones, forman parte de la misma inquietud de reconocimiento, de libertad y de romper con un sistema de exclusión brutal. El campo de la negociación muchas veces no es propuesto por quienes demandamos estos cambios, sino que se encuentra armado con anterioridad como algo supuestamente "natural" o, por lo menos, conveniente para quienes ya no pueden justificar la existencia del sistema ético-social imperante en la doctrina o en lo biológico, pero que se aferran a este ordenamiento con el objeto de seguir percibiendo los beneficios que les ha traído cierta estructura de los afectos o, utilizando un concepto Foucaultiano, una "ética de los afectos" que se ha establecido como paradigma en la era de la modernidad. No es que sea un grupo determinado de sujetos quienes han implementado este orden y lo han preservado por generaciones, sino más bien es una red de sujetos: hombres y mujeres de diversos ámbitos del deseo que han reproducido un discurso del "buen amor"; este concepto se estableció en América Hispana como el campo fecundo y productivo para que el amor de pareja sea consumado dentro de la institución matrimonial, dado que este amor era considerado como el origen de la familia, la cual constituía la célula primordial de la sociedad. 


\section{S\&e \\ sonerewo}

En este sistema de ordenamiento podemos apreciar claramente los márgenes que se han establecido para permitir nuestro limitado transitar con algún sentido de libertad, en el sentido "liberal" del término, determinando cuáles son las áreas iluminadas y cuáles las áreas proscritas habitadas por los sujetos de la disidencia. Al habitar estas áreas, cada quien en el lugar que le fue asignado, lo justificamos, manteniendo la dualidad entre hegemonía y marginalidad. Es justamente esta relación que sostiene el sistema liberal, capitalista y heterosexista, la que quisiera poner en entredicho en este artículo, evidenciando las estrategias de reacomodo y negociación que se han establecido entre ciertos movimientos gay y los sectores conservadores de nuestra sociedad, con el objeto de visibilizar las cooptaciones y posibles trampas que el mismo sistema heterosexista contempla para su subsistencia; ahondando en las políticas asimilacionistas, de reconocimiento y de la diferencia.

\section{La Interpelación y la Construcción del Deseo}

Este sistema de ordenación en el que estamos insertos, ha marcado sus signos sobre el cuerpo y el espacio estableciendo una dinámica entre ambos elementos. Esta relación de la corporalidad se nutre del lenguaje, la palabra y el deseo, los que constituyen marcas; tal como lo señala Beatriz Preciado, el cuerpo se signa de estas marcas adjudicando un valor a cada espacio: "El cuerpo hetero (straight) es el producto de una división del trabajo de la carne según la cual cada órgano es definido por su función. (...) De este modo el pensamiento heterocentrado asegura el vínculo estructural entre la producción de la identidad de género y la producción de ciertos órganos como órganos sexuales y reproductores. Capitalismo sexual y sexo del capitalismo"2. La ideología y el sistema económico bajan un telón de fondo en el desarrollo y regulación del cuerpo y del deseo.

Según la tesis de la "performatividad" propuesta por Judith Butler, la identidad genérica es la ostentación de una serie de signos que teatralizamos sobre nuestros cuerpos. La forma como nos vestimos, nos movemos, nos sentamos, las palabras que usamos e incluso nuestro tono de voz, todo nos remite a una categoría impuesta. Este pensamiento se encuentra al servicio de un sistema ideológico de la producción de sujetos basados en la sexualidad; en consecuencia, el género y la heterosexualidad son construcciones políticas armadas bajo un programa de intereses. En este punto es necesario precisar que, si bien las ordenaciones del deseo son construcciones históricas y producidas, transformadas e, incluso, rescatadas en diversas culturas, sus estructuras se encuentran tan arraigadas en los procesos culturales, lingüísticos y cognitivos de las sociedades que no es fácil su deconstrucción; inclusive los esencialismos identitarios

\footnotetext{
${ }^{2}$ Preciado, Beatriz. Las Multitudes Queer. Notas para una política de los "anormales". Revista Multitudes. $N^{\circ}$ 12. París, 2003.p.3.
} 


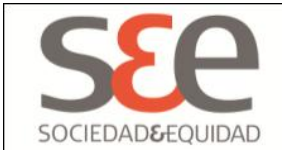

pueden concebirse en este ámbito y ser tan rígidos como los esencialismos biológicos. Foucault, a este respecto, con un pesimismo evidente, señalaba que los discursos con "carácter de verdad" son tan eficientes en su accionar que no es posible atacarlos de una manera frontal, sino transversalmente, evidenciando sus mecanismos de ordenación y los intereses que subyacen por detrás de las agencias que los manipulan.

Los cuerpos y la identidad del deseo se constituyen en un acto de "interpelación", lo cual nos identifica con una serie de códigos colectivos. Cada vez que nombramos al cuerpo planteamos los signos discursivos sobre la materia; es como si transitáramos con un ropaje cultural sobre el cuerpo biológico. Todo este proceso de control mediante la normatividad es posible porque la palabra tiene un carácter "constituyente" de la realidad; se asume lo que se dice y se asocia al imaginario. Pero estas asociaciones no son fijas y pueden ser resignificadas mediante nuevos actos de apropiación. Es lo que Butler ha señalado como enunciación preformativa, la cual nos constituye identitariamente ocultando las evidencias de este proceso y generando la ilusión de que este sujeto ya estaba constituido antes de su operación; un sujeto que supuestamente existe desde siempre, es decir, un sujeto esencial que antecede al sujeto social, lo que justifica la existencia misma del sistema. Bajo este prisma nuestras historias de vida parecieran proyectarse en el pasado; cada signo, acción o señal la ordenamos dentro de este plano discursivo. Así, afirmamos con frecuencia que somos hombres o gay o heterosexuales porque desde siempre se ha manifestado en nosotros la esencia identitaria de esta condición. Nos situamos en un lugar el cual nos sentimos impelidos a ocupar sin percibir que este sitial ha sido determinado por alguna agencia de poder; este proceso ciertamente tiene interés político. $Y$ es lo que Michel Foucault ya había señalado como la estrategia del poder/saber determinando quién tiene la autoridad para constituirse en sujeto de enunciación, es decir, en sujeto de conocimiento, y quién es el objeto de ese discurso, quién tiene derechos y quién carece de ellos.

El Yo y el Otro se conforman en esta dinámica de exclusiones e inclusiones donde lo abyecto no se concibe como lo foráneo, sino como un elemento constitutivo de identidad del mismo modo que lo canónico. Participamos del ordenamiento del sistema identitario por opresor que éste sea y lo fortalecemos en esta dualidad entre hegemonía y marginalidad. La conformación identitaria es siempre un acto colectivo en el cual se asumen los deseos de las agencias significantes; Judith Butler señala a este respecto: "aunque ser de cierto género no implica que se desee de una cierta manera, existe no obstante un deseo que es constitutivo del género mismo y, como consecuencia, no se puede separar de una manera rápida o fácil del género de la vida del deseo. ¿Qué es lo que quiere el género? Hablar de esta manera puede parecernos extraño, pero resulta menos raro cuando nos damos cuenta de que las normas sociales que constituyen nuestra existencia conllevan deseos que no se originan en nuestra individualidad"3.

\footnotetext{
${ }^{3}$ Butler Judith (2006). Deshacer el género. Barcelona: Paidós. p. 14.
} 


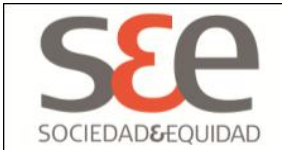

\section{Resignificando la Injuria}

En esta dinámica de lo normal y lo abyecto constituido en el acto de interpelación, la primera imagen que tenemos de nuestra identidad como sujetos abyectos se desprende de la injuria; cuando escuchamos el insulto o la degradación que nos significa como maricones, invertidos, putas y pecadores, asumimos que nuestro carácter principal nos distancia de un todo, constituyéndonos en lo otro. El insulto se asume en toda su violencia e impulsividad signando una marca en las estructuras psíquicas y afectivas de los individuos; es como un golpe que deja una huella latente en nosotros; es en sí la marca misma de la dominación, constituida en agresión con el fin de someter y ordenar. Los receptores de la injuria la asumimos con prontitud situándonos en el ámbito que consideramos nos corresponde, generalmente sin cuestionar el orden establecido; la injuria se constituye, en consecuencia, en el vínculo entre la dominación y la subordinación. La injuria también actúa como cohesionador de un determinado sistema de ordenamientos; de esta forma, los sujetos signados como abyectos, son signados con la marca de Caín por el sistema que busca en la inmolación de estos sujetos el fortalecimiento del propio ideal identitario heterosexista.

En este escenario, nuestra única reacción posible es o adecuarnos a los códigos que nos permitan cierta aceptación, o bien escapar, pero ¿hacia dónde? si todo el sistema se encuentra constituido desde un epicentro hegemónico. Si bien existe la posibilidad de constituir otras estructuras, éstas pueden mantener ciertos signos residuales del antiguo ordenamiento de opresión; los signos se reajustan y se transforman, pero las estructuras en las relaciones del poder no transforman del todo la ecuación. Ante este magro escenario muchos optan por asumir una política de la simulación o del closet; esto permitiría compartir cierto estatus dentro del sistema de ordenación social y simbólico, pero esta acción no es completamente exitosa, pues tal como lo señala Didier Eribon, ${ }^{4}$ siempre quedará un margen de culpa y de miedo ante lo abyecto. El insulto no solo afecta a aquellos a quienes va dirigido, sino que también a quienes lo comprenden en su agresividad y sienten en secreto que forman parte de este ámbito marginal. Finalmente solo nos queda la posibilidad de la huida hacia espacios más amigables y al encuentro de otros como nosotros.

Es revelador que el primer artículo del FAHR publicado en la Revista "Liberation" en Francia se titulara justamente "A los que son como nosotros", evidenciando el anhelo de forjar una comunidad que nos contenga y que sirva de fortaleza contra los ataques e injurias. Antes de la irrupción de Internet, estos ámbitos adquirían el carácter de gueto; era necesario ser ingresado en un mundo de iniciados, donde los códigos y los espacios pudieran develar cierta complicidad. Una vez dentro se constituía una red de protección reproduciendo los mismos modelos conocidos, por ejemplo la familia nuclear, que es el símbolo más patente de la ordenación heterosexista, se re-configura como un ámbito de

\footnotetext{
${ }^{4}$ Eribon, Didier (2001). Reflexiones sobre la Cuestión Gay. Barcelona: Anagrama.
} 


\section{S\&e \\ somenow}

protección con nuevos códigos de género y del deseo; una madre gay, un padre gay y muchos hermanos que comparten sus secretos y pasiones. De esta forma se resignifican los mismos códigos de la opresión.

\section{Las políticas asimilacionistas}

Históricamente los sujetos denominados como abyectos han sido víctimas de abusos y muchas veces despojados del status de dignidad humana. El concepto de humanidad es atribuido y despojado con arbitrariedad por las agencias de normalización que han existido desde siempre. Judith Butler asume esta problemática y establece que esta discriminación mantiene caracteres siempre indivisibles de sexismo, racismo y clasismo; de esta forma, la condición humana, tal como se ha establecido desde los márgenes de la hegemonía, conlleva un modelo racial, sexual, de género y de clase determinado ${ }^{5}$.

Es claro que hemos asumido y aceptado una forma de humanidad que se ajusta a los requisitos afectivos y reproductivos de un modelo determinado; así los individuos que transitan entre las fisuras del modelo como transgéneros y personas intersexuadas, son obligados a la definición y el ajuste de sus mecanismos corpóreos y deseantes.

En este contexto, la identidad gay ha aspirado a un reconocimiento por parte de la masculinidad hegemónica, la cual le ha otorgado, muy a su pesar, un estatus formal dentro de la institucionalidad. Pero esta política de la asimilación deja fuera muchas otras prácticas diversas dentro de los márgenes de la sexualidad. Judith Butler ya lo señalaba con respecto al matrimonio homosexual: "Los recientes esfuerzos para promover el matrimonio de lesbianas y gays promueven también una norma que amenaza con convertir en ilegítimas y abyectas aquellas configuraciones sexuales que no se adecuen a la norma del matrimonio ni en su forma actual ni en su forma corregible"6.

El reconocimiento conlleva a una normalización y cooptación de otras formas de concebir el deseo. Al establecer esta alianza del reconocimiento, la identidad gay condena a todas aquellas formas que escapan a ella, aunque no lo haga explícitamente; los ritos a los cuales se adhieren, que son los ritos que han conformado la institucionalidad heterosexista, arrojan un velo oscuro sobre las formas de placeres disidentes. Con la consumación de las políticas del matrimonio igualitario, se podría señalar que ya no hay justificación para mantener prácticas sexuales fuera de esta institucionalidad; de alguna forma entramos, con esto, a un nuevo nicho de control. "Para luchar contra la opresión se necesita comprender que nuestras vidas se sostienen y mantienen de forma diferencial", una diferencia que radica no solo en la elección del objeto del deseo sino, como ya se ha señalado, en todo un sistema valórico y de prácticas afectivas y sexuales.

\footnotetext{
${ }^{5}$ Butler op. Cit, pp. 29-30.

${ }^{6}$ Butler Judith (2006). Deshacer el género. Barcelona: Paidós. Pp. 18-19
} 


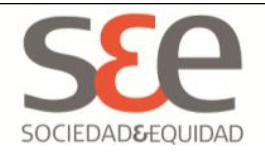

Es comprensible que muchos movimientos gay se hayan empeñado en adquirir un reconocimiento en su calidad de seres humanos, en su calidad social, jurídica y política, pero el reconocimiento, ante quienes anteriormente habían negado esa condición, no es un avance sino más bien una legitimación de su posición hegemónica en el Sistema. Estas alianzas corporativistas del deseo que nos asimila a otros y otras como un todo "humanizado", desconocen justamente lo principal: nuestras diferencias. La identidad gay, en su afán del reconocimiento hegemónico, ha tratado de cohesionar y uniformar las identidades de marginados, con o sin representatividad; se ha arrogado el pronunciamiento de todos los desconocidos y se ha tornado en el sello aliancista, pero a un muy alto costo, el de nuestra autonomía.

Otro de los aspectos que me parece preocupante dentro de la conformación de la identidad gay, es el culto a las claves tradicionales de la masculinidad, esforzándose por mantener el nexo con la masculinidad hegemónica heterosexista y, con ello, los signos de prestigio y poder que les son propios. Estas concesiones del modelo mascultista a identidades masculinas emergentes como la identidad gay, no significan una apertura para quienes se desplazan por ámbitos disidentes. También es necesario hacer mención que este anhelo de reconocimiento no se opone a los intereses del sistema establecido, ya que la política identitaria es parte de la maquinaria que hace funcionar todo el sistema liberal, por lo cual al consolidar una identidad se reafirma con ello todo el sistema de opresión y control que hemos combatido.

La asociación se ha presentado falsamente como un derecho y no más bien como dispositivo alienador; tal como señala Butler, el yo individual cede su paso ante los otros, quienes diagraman nuestro cuerpo y nuestra identidad. "Sin duda, el matrimonio y las alianzas familiares del mismo sexo deberían ser una opción disponible pero convertirlas en modelo para legitimidad sexual es precisamente constreñir la sociabilidad del cuerpo de una forma aceptable"7.

Si bien la validación de una forma alternativa de relacionamiento es necesaria, dicha validación no puede pasar por ajustarse a los códigos y dispositivos de control de las agencias heterosexistas y liberales. Es necesario constituir un nuevo sistema de ética que se aplique no solo a la homoerótica sino a todos, sin la necesidad de constituir una identidad del deseo determinada. Tal como lo señala Foucault, no es la opción sexual en definitiva lo que inquieta al sistema heterosexista, sino el establecimiento de un modelo relacional afectivo y valórico alternativo ${ }^{8}$.

El matrimonio igualitario se ha constituido en el emblema de todas las reivindicaciones, opacando incluso una tan necesaria ley de anti-discriminación sexual. En ese contexto

\footnotetext{
${ }^{7}$ Butler op. Cit. P. 47.

${ }^{8}$ Hago notar que en este ensayo establezco una férrea unión entre movimiento gay e identidad gay en el contexto que considero que la identidad gay se ha establecido como una identidad política dependiente de la identidad de reivindicación.
} 


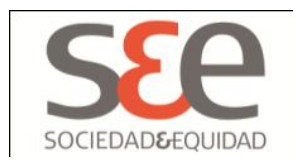

difícilmente podría haber cabida para otras formas de relacionamiento que no fuesen las que han sido impuestas por las mismas alianzas liberales en torno a la sexualidad y la familia. ¿Qué sucedería, entonces, con todos quienes no nos ajustamos a este modelo y que antaño habíamos sido confundidos indistintamente dentro del ámbito de la perversidad?. Me refiero no solo a hombres y mujeres que asuman una orientación homoerótica, sino también a todos aquellos que traspasan las líneas de lo permisible. El matrimonio posibilita la conquista de estos espacios en blanco con un valor establecido desde lo hegemónico.

En consecuencia, las prácticas del deseo marginal se tornan subversivas; ¿pero por qué entrañan tanto peligro para el sistema hegemónico estas prácticas marginales? Sencillamente porque no se ajustan a un modelo binarista del deseo, un modelo que reafirme y sostenga los intereses de producción liberal, esto es la familia nuclear y el modelo afectivo sexual binario. Butler señala a este respecto: "No obstante, a aquellos que viven fuera del marco conyugal o que mantienen modos de organización social para la sexualidad que no son monógamos, ni cuasi maritales se les considera crecientemente como irreales, y sus amores y pérdidas como menos amores "de verdad" y menos pérdidas "de verdad"9 . De alguna u otra forma se viene a ratificar lo que Michel Foucault señalaba respecto a los mitos sobre el estilo de vida homosexual, sobre su desenfrenada sexualidad que empuja a los hombres gays a practicar tantas experiencias sexuales como puedan antes de alcanzar el clímax orgásmico; el heterosexismo ha calificado a la "gaydad" (el término de David Halperin) de superficial e incapaz de generar relaciones de amor estables y productivas. Las políticas matrimoniales constituirían, de esta forma, el sello de confianza otorgado por el heterosexismo, para asegurar un ordenamiento heterosexual sobre los afectos y la sexualidad de los gays; estos se mantendrán bajo la égida valórica que se ha establecido como universal y aceptable. Todos quienes insistan en mantenerse al margen de este sistema serán doblemente enjuiciados: por la identidad del deseo y por la opción de no aceptar la monogamia como única forma de relación sexual y afectiva. Hay que estar atento a estas nuevas estrategias de coaptación que incluirían a algunos y algunas y necesariamente sancionarán a otros y otras, no por las prácticas sexuales en si mismas, sino por cómo se establecen en un orden social. Tal como lo señala Foucault, no es la opción sexual en definitiva lo que inquieta al sistema heterosexista, sino el establecimiento de un modelo relacional afectivo y valórico alternativo ${ }^{10}$.

Las desviaciones son percibidas como un peligro nocturno el cual debe ser recluido en nichos marginales. A este respecto, Leo Bersani señala: “...la intolerable promesa de "tipos de relaciones impensadas" que muchas personas ven en los tipos de vida gay no puede disociarse de una organización auténticamente nueva de placeres del cuerpo; y

\footnotetext{
${ }^{9}$ Op. Cit, p.48.

${ }^{10}$ Hago notar que en este ensayo establezco una férrea unión entre movimiento gay e identidad gay en el contexto que considero que la identidad gay se ha establecido como una identidad política dependiente de la identidad de reivindicación.
} 


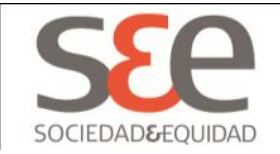

señalar que ese programa tal vez implique necesariamente algún experimento radical, y hasta peligroso, con modalidades de lo que solía llamarse hacer el amor"11.

\section{Políticas de la Diferencia}

En este escenario diagramado por la "norma" heterosexista, las relaciones se arman también signadas en este ordenamiento y tendemos a reproducir los mismos sesgos afectivos, sexuales y familiares desarrollándonos dentro de los márgenes de relaciones monógamas y el deseo. De esta forma, muchos sectores conservadores han intentado mantener el control de los espacios abyectos recluyendo toda acción que se vea reñida con este modelo en guetos ocultos pero no invisibles al ojo fiscalizador.

Siendo percibidas estas acciones como desviaciones, se asumen como aisladas, fuera de la colectividad e incapaces de generar una ética afectiva y relacional. El sistema de ordenamiento se empeña en mantener esta imagen de lo abyecto como extravío ya que, como se ha señalado, fortalece la ilusión de la normalidad asociada al orden establecido. Es por ello que cualquier acción que no implique una ruptura radical con este sistema, simplemente lo reafirma, perpetuando la dialéctica establecida entre normalidad y desviación. Al aceptar que existen otras formas de ordenación de la afectividad y la sexualidad, desarticulamos el eje de poder de las mismas agencias conservadoras que hasta ahora nos han ofrecido, simplemente, un reconocimiento parcial de derechos. No es casualidad que, ante el avance de los movimientos gay y feministas, los mismos sectores de ultranza conservadora se reorganizaran y establecieran propuestas que parecieran innovadoras, en relación a la regulación de prácticas afectivas anteriormente consideradas como antinaturales o pecaminosas. Sin embargo hay que poner atención ante estas acciones, ya que pueden significar meras estrategias y reacomodos; así lo señalaba Beatriz Jimeno en su visita a Chile hace un par de años en referencia al proceso de lucha de los movimientos gay y lésbicos por el matrimonio igualitario en España, señalando que, a medida que este movimiento cobraba fuerza, los sectores más conservadores y radicales, incluida la Iglesia Católica, propusieron programas de regulación para uniones "no matrimoniales"; de esta forma pretendían asimilar este proceso al sistema sin infringir la norma heterosexista. Siento que algo similar está ocurriendo en nuestro país; vivimos un momento de movilizaciones y reivindicaciones en muchos ámbitos que pudiéramos resumir como un descontento con el sistema sexual y económico existente, relación no ajena entre sí, ya que el sistema liberal capitalista también capitaliza los cuerpos y la sexualidad. Es por ello que no me extraña que sea justamente este gobierno, el cual mantiene relaciones con los sectores más conservadores, el que finalmente proponga nuevas alianzas y negociaciones con los movimientos de identidad gay. Tampoco es de extrañar que dichos movimientos acepten estas negociaciones ya que, tal como he señalado, existe un ansia de reconocimiento y validación latente de parte de quienes hemos sido expuestos como lo marginal. Pero debemos estar alertas hasta dónde debemos ceder, si estas

\footnotetext{
${ }^{11}$ Bersani, Leo (1995). Homos. Buenos Aires: Manantial.
} 


\section{S\&e \\ SOCIEDADEEQUIDAD}

negociaciones implican generar nuevas exclusiones para todos aquellos sujetos que no se adapten a los modelos de relaciones monógamas quedando excluidos, nuevamente, por la ley y la moral, entonces no estamos consiguiendo una modificación real del sistema heterosexista.

No es que en lo personal considere los programas de los movimientos gay improducentes, sino más bien considero que no se debe poner como emblema de este proceso únicamente al matrimonio ni tampoco aceptar una forma de relacionamiento que reproduzca las formas existentes. Creo antes conveniente centrarnos en conseguir una ley antidiscriminatoria que incluya la posibilidad de relacionamientos diferentes y prácticas sexuales que aún hoy son penalizadas, como los encuentros sexuales en espacios del deseo homoerótico u otras que pudieran surgir en un ambiente más tolerante.

Si asumimos una nueva ética de las afectividades que estructure nuestros relacionamientos, entonces habremos dado un paso por escapar a las formas heterosexistas de ordenación en cuanto al matrimonio y el parentesco. Butler bien lo señala: "cuando estos modos de asociación íntima producen redes de relaciones sostenibles constituyen una 'ruptura' del parentesco tradicional que desplaza la suposición que asume que la estructura de la sociedad se centra en las relaciones biológicas y sexuales"12. De esta forma, las relaciones permanentes y asociativas pueden fundarse ya no en los márgenes del matrimonio sino en una ética de la afectividad y la amistad.

En este contexto, las políticas queer, al resistirse a la cristalización del deseo, nos permiten una amplitud y apertura en las prácticas de los placeres y con ello una identidad no monolítica. Michel Foucault ya lo señalaba a principio de la década de los años setenta al enfrentarse a las políticas del FHAR y de su líder Guy Hocquemheim, aludiendo que una política identitaria limitaría nuestro accionar generando células de vigilancia. En este punto es necesario hacer una observación, pues en varias oportunidades he escuchado a simpatizantes de las políticas queer aseverar que las prácticas de esta índole nos conducen a una no identidad. Pero las prácticas queer no apuntan a este blanqueamiento identitario, sino a un deslizamiento; tal como señala Butler, no se trata de oponerse a la identidad sino más bien al control de ella ${ }^{13}$.

\footnotetext{
${ }^{12}$ Butler, Op. Cit. P. 47.

${ }^{13}$ Butler, Op. Cit. P. 22.
} 


\section{S\&e}

\section{Conclusiones}

En conclusión, podemos señalar que el punto crucial en esta discusión es el reconocimiento identitario, la visualización de una forma de vida que, a la vez, nos vulnerabiliza haciéndonos presa fácil de las agencias de control. El reconocimiento conlleva a una normalización y cooptación de las formas marginales, de las resistencias, de estas otras formas de concebir el deseo. Esta es la alianza que se ha establecido entre la masculinidad hegemónica y la identidad gay. Al establecer esta alianza del reconocimiento, la identidad gay condena a todas aquellas formas que escapan a ella, aunque no lo haga explícitamente; los ritos a los cuales se adhiere, que son los ritos que han conformado la institucionalidad heterosexista, arrojan un velo oscuro sobre las formas de placeres disidentes. Con la consumación de las políticas del matrimonio igualitario se podría señalar que ya no hay justificación para mantener prácticas sexuales fuera de esta institucionalidad; de alguna forma entramos con esto a un nuevo nicho de control. "Para luchar contra la opresión se necesita comprender que nuestras vidas se sostienen y mantienen de forma diferencial", una diferencia que radica no solo en la elección del objeto del deseo sino, como ya se ha señalado, en todo un sistema valórico y de prácticas afectivas y sexuales.

Necesitamos una política de la sexualidad donde se incluyan más formas de expresión sexual; donde se consideren, del mismo modo, las prácticas que hasta ahora se consideraban abyectas, marginales, nocivas. Los encuentros sexuales clandestinos, ocultos en la ciudad y los espacios públicos que han significado hasta el día de hoy infracciones no solo legales, sino también morales, han sido por generaciones sancionados condenados Requerimos apropiarnos nuevamente de todos los espacios y no conformarnos con los que nos entregan quienes han controlado por siglos nuestra moral, afectos, expresiones y deseos; necesitamos movilizarnos para no caer en limitadas negociaciones que representan el reconocimiento tan solo de un sector.

\section{Referencias Bibliográficas}

Butler, Judith (2006). Deshacer el Género. Barcelona: Paidos.

Bersani, Leo (1995). Homos. Buenos Aires: Manantial.

Bordieu, Pierre (2000). La dominación masculina, Barcelona: Anagrama.

D'Emilio, John (1983). El capitalismo y la indentidad Gay (traducción de César Ayala de "Capitalism and gay identity", en Powers of Desire, Ann Snitow y otras (comp.), Nueva York: Monthly Review.

Eribon, Didier (2001). Refexiones sobre la cuestión gay. Barcelona: Anagrama. 


\section{s\&e}

Foucault, Michel (2004). El nacimiento de la clínica. Buenos Aires: Siglo XXI Editores.

Foucault, Michel (2004). Vigilar y castigar. Buenos Aires: Siglo XXI Editores.

Foucault, Michel (2002). La Hermeneutica del Sujeto, Curso en el Collège de France (1981-1982). México: F.C.E.

Foucault, Michel (2000). Los Anormales, Curso en el Collège de France (1974-1975). México: F.C.E.

Foucault, Michel (1998). Historia de la locura. México: F.C.E.

Foucault, Michel (1996). Historia de la sexualidad, La voluntad del saber, El uso de los placeres. Madrid: Siglo XXI Editores.

Foucault, Michel (1995). Tecnologías del yo. Barcelona: Paidos.

Halperin, David (2004). San Foucault. Buenos Aires: Ediciones Literales.

Monsivais, Carlos (2004). La lucha de las comunidades marginales por la visibilidad. Debate feminista, № 17.

Preciado, Beatriz (2003). Las Multitudes Queer. Notas para una política de los "anormales". Revista Multitudes. № 12. París. 